\title{
Comment on: Singapore Medical Journal in the age of social media
}

Singapore Med J 2021; 62(7): 366 https://doi.org/10.11622/smedj.2021094

Dear Sir,

As medical students studying in the United Kingdom, we found the editorial "Singapore Medical Journal in the age of social media"(1) to be of great interest. Being medical students who use social media, we agree that the Internet brings opportunities and supports the Singapore Medical Journal in its efforts to engage with social media.

Literature regarding the impact of sharing medical research on social media and on patient care is lacking, and further research is needed. The main oversight identified in this article, in our view, is the lack of consideration for commonly seen "tribal behaviours of clinicians that may continue to limit knowledge sharing", as identified by Rolls et al. ${ }^{(2)}$ Therefore, it is imperative for the journal to consider its readership and social media content to reach a diverse range of readers.

Recent evidence has shown that 'tweeting' articles results in significantly more article citations over time. ${ }^{(3)}$ In the future, medical journals may have social media teams who compete to reach the most people on social media and thus receive more citations and a higher journal impact factor.

To conclude, this editorial considers the future of the Singapore Medical Journal and opines that social media will become more important in medical publishing. However, the authors could also acknowledge that using social media can restrict the potential audience reached. This is because social media accounts must be checked regularly and also 'follow' the accounts being used to share information relating to journal articles. Without these two conditions, there is limitation in who will see, and therefore interact with such spreading of knowledge.

Yours sincerely,

Daniel Joseph Warrington ${ }^{1}$, Gavin Hellyar Treleaven $\underline{\text { Ball }}^{1}$

${ }^{1}$ Faculty of Medicine, Biology and Health, University of Manchester, Manchester, United Kingdom. daniel_warrington@hotmail.co.uk

\section{References}

1. Ng CL, Poh KK. Singapore Medical Journal in the age of social media. Singapore Med J 2020; 61:501-2.

2. Rolls K, Hansen M, Jackson D, Elliott D. How health care professionals use social media to create virtual communities: an integrative review. J Med Internet Res 2016; 18:e166.

3. Luc JGY, Archer MA, Arora RC, et al. Does tweeting improve citations? One-year results from the TSSMN prospective randomized trial. Ann Thorac Surg 2021; 111:296-300. 